\title{
A Sociolinguistic Study of Class Identification of Thai Middle Class
}

\author{
Asst. Prof. Dr. Pattamawan Jimarkon \\ King Mongkut's University of Technology Thonburi, Thailand
}

\section{Doi:10.5901/ajis.2013.v2n3p403}

\section{Abstract}

\begin{abstract}
In an average nation, the middle class is the portion of population that drives the nation politically, economically and culturally and always continues to grow larger in size. The middle class are typically more active and vocal to participate in their discourse community and, at present, better compatible with Internet technologies that allow synchronous and asynchronous communication. Thailand has seen a turbulent societal division and political polarization in recent years. The long-standing conflict is rooted from the enormous socio-economic gap between the middle class to the rich and the grassroots. $A$ sociolinguistic analysis of online discourse can help theorising the social and contextual characteristics of class identification made by the middle class who has the most Internet access. The data of the study will be a collection of online discussion from a Thai public website between March 1-31, 2013. The data will be entirely in Thai but will be translated into English for result reporting and discussion. Following Herring (2004) on researching virtual identity, the study will address the middle class's shared history, purpose, culture, norms and values by investigating group-specific language use, jargon, language routines as well as choice of language. Self-awareness of the middle class group by the members' terms of address as a group such as 'us vs. them' will also be identified.
\end{abstract}

\section{Introduction}

'Middle class' can be termed for cultural, social or historical significances. In developing countries where economic growth allows the middle class to continue to expand, the term 'middle class' addresses those living above the median poverty line or even if still poor (Ravallion, 2010). This is particularly true for Thailand.

"Thai society is loosely structured", allowing "a high rate of status mobility" (Evers, 1966, p. 481). Urbanisation brings about changes of practice and organisation into the new social order. In a society structured by class like Thailand, conflicts between classes are inevitable (Evers, 1988). The political conflicts are tearing apart Thailand into classes and social divisions.

Public discourses mirror the social reality. As the key group to drive the national and societal conditions, they are typically more active in voicing issues like infrastructure, education and industry. Computer technologies are an important thing to provide them with the skills to help them gain employment, whatever they may be. Social media nowadays is more than a form of networking. It is everything, from a marketplace to a classroom and even a lecture hall.

This sociolinguistic analysis of online discourse can make visible class identification made by the middle class through the perspective of virtual identity. It explores how the middle class Thais manifest their class identities in the public sphere.

\section{Literature Review}

Language is the evidence that people want to belong in the society. Features and characteristics of language are utilized to, through language, display the faithfulness to a particular group and, in turn, form a discursive identity (Yus, 2001). In Koller (2012), collective identities in discourse were investigated through the linguistic and semiotic description of textual features to uncover beliefs and knowledge, norms and values, attitudes and expectations as well as emotions, and as being reinforced and negotiated in discourse. Critical discourse analyses such as this one can make possible the awareness of discourse practice as well as to the social context that influences it.

The online environment provides opportunities to make friends, or foes, and to share interests with others. A survey study about computer and human behavior (Buote, Wood \& Pratt, 2009) found that online friendships may be formed in similar ways as offline ones but the degrees and quality of attachment vary. The online community, although an abstract concept, it is a common ground that functions almost like a playground or a football field.

Virtual identity or online identity has been a prevalent focus of investigation in the last two decades. One notion 
that lies behind this interest is 'authenticity', we want to increase the confidence that we know the person who they say they are and they are not pretending to be someone else or something else.

As far as online identity construction is concerned, it is quite interesting to see what kind of information and identification people are willing to reveal with other members of the online community to show who they are and what/who they identify themselves with. In a formal context such as academic homepages in Hyland (2011), it was found that academics manifested their personal images and identities in their discourses despite the control for them to maintain professional looking by their employers. Online identities like these are constructed for the audience to experience.

In the online environment, individuals see themselves and want others to perceive the identities they have adopted. With that identity, a person sees him/herself as part of the community and responds to the norms and values set by the group.

Many sociolinguistic studies on online identities draw on linguistic features as evidence of explanations in social life. An analysis of the French tu or vous could tell us a great deal about identities and relationships of people in the aspect of internet romance (van Compernolle, 2008), for example.

\section{Data Analysis}

The data of the study was a collection of online discussion from a Thai public news website manager.co.th between March 1-31, 2013. The topics of discussion ranged from politics, economy and celebrity news. The data was entirely in Thai but was translated into English for result reporting and discussion. Due to space limitation, only 15 postings were selected to be included in the analysis and discussion. First each of the postings was identified as a reference to 'middle class', 'upper class' or 'lower class' based on any linguistic evidence or contents of the posting. Then the data was analysed using the framework adopted from Herring (2004).

Herring (pp. 14-5) compiles six sets of criteria to investigate the identity of virtual identity. To characterise participation on virtual community, it was a useful departure for analyzing the participation discourse in threads or other extended discourse samples constitute their identities. They are 1) active participation, 2) shared history, 3) solidarity, 4) criticism and conflict, 5) self-awareness, and 6) emergence of role.

As the focus of this study was placed on the uniqueness of the discourse on class identity, it was to be appropriate to addresses only criteria 2-5. The data was investigated for the following characteristics and the intentional lack thereof.

Table 1: Data Analysis Criteria Inspired by Harring (2004)

\begin{tabular}{|c|c|}
\hline \multicolumn{2}{|r|}{ Shared history, purpose, culture, norms and values } \\
\hline o & $\begin{array}{l}\text { Culture is indexed through the use of group-specific abbreviations, jargon, and language routines as well as through } \\
\text { choice of language, register, and dialect } \\
\text { Norms and values are revealed through an examination of netiquette statements and verbal reactions to violations of } \\
\text { appropriate conduct (judgment, evaluation) } \\
\text { group-specific language use, jargon, language routines as well as choice of language. }\end{array}$ \\
\hline \multicolumn{2}{|r|}{ Solidarity, support, reciprocity } \\
\hline o & $\begin{array}{l}\text { the use of verbal humor, support through speech act analysis focusing, e.g., on acts of positive politeness; and } \\
\text { reciprocity through analysis of turn initiation and response } \\
\text { a scale of perceived like-mindedness or similarity of behavioral disposition between } \\
\text { a speaker and addressee deriving from their similar backgrounds acquaintance, or personal characteristics, such as } \\
\text { social status. }\end{array}$ \\
\hline \multicolumn{2}{|r|}{ Criticism, conflict, means of conflict resolution } \\
\hline $\begin{array}{l} \\
\circ \\
\circ \\
\circ\end{array}$ & $\begin{array}{l}\text { negation, } \\
\text { reject and deny ideas and statements } \\
\text { create a conflict or resolve a conflict }\end{array}$ \\
\hline \multicolumn{2}{|r|}{ Awareness of group as an entity distinct from other groups } \\
\hline $\begin{array}{l}\circ \\
\circ\end{array}$ & $\begin{array}{l}\text { the central concept that group members accept as the property of the individual belonging to the group or the identity } \\
\text { of the group as a whole. } \\
\text { Awareness of properties that are not associated with the group } \\
\text { Self-awareness of the middle class group by the members' terms of address as a group such as 'us vs. them' will } \\
\text { also be identified. }\end{array}$ \\
\hline
\end{tabular}


Table 2 Analysis of comments according to four criteria of virtual identity

\begin{tabular}{|c|c|c|c|c|c|}
\hline & Comments & Shared culture & Solidarity/ & $\begin{array}{l}\text { Criticism/ } \\
\text { Conflict resolution }\end{array}$ & Group awareness \\
\hline & Middle Class & & & & \\
\hline 1 & 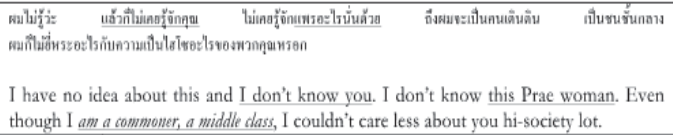 & & $\begin{array}{l}\text { Show indifference } \\
\text { to display different } \\
\text { backgrounds. }\end{array}$ & & \\
\hline 2 & 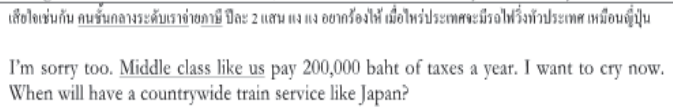 & $\begin{array}{l}\text { Show } \quad \text { shared } \\
\text { distress }\end{array}$ & $\begin{array}{l}\text { Display group } \\
\text { solidarity by } \\
\text { pronoun 'us'. }\end{array}$ & & $\begin{array}{l}\text { State the property } \\
\text { of group. }\end{array}$ \\
\hline 3 & 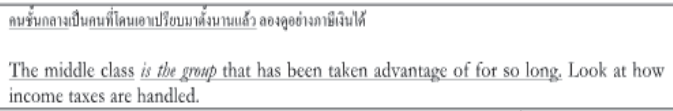 & Reveal a shared fate. & $\begin{array}{l}\text { Use unspecific term } \\
\text { of address to } \\
\text { represent own } \\
\text { group. }\end{array}$ & & \\
\hline 4 & 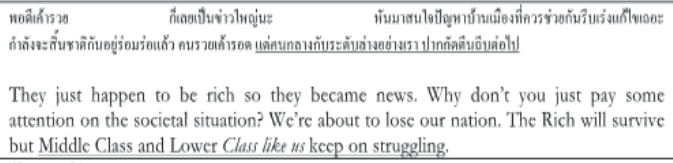 & & $\begin{array}{l}\text { Generalize group } \\
\text { social status. }\end{array}$ & & \\
\hline & Upper Class & & & & \\
\hline 5 & 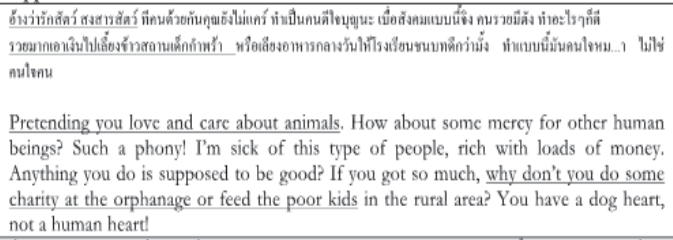 & $\begin{array}{l}\text { Impose a group } \\
\text { valuc. }\end{array}$ & & $\begin{array}{l}\text { Make a criticism } \\
\text { based on a disbclicf. }\end{array}$ & \\
\hline 6 & 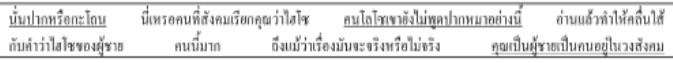 & & & & \\
\hline
\end{tabular}

\begin{tabular}{|c|c|c|c|c|c|}
\hline & Comments & Shared culture & Solidarity/ & $\begin{array}{l}\text { Criticism/ } \\
\text { Conflict resolution }\end{array}$ & Group awareness \\
\hline & 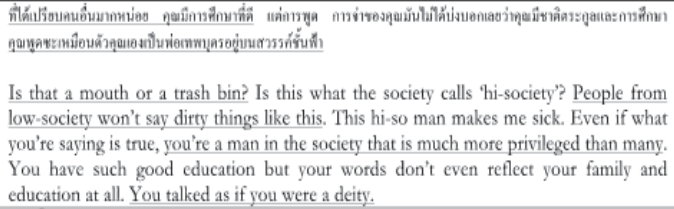 & $\begin{array}{l}\text { Place a value based } \\
\text { on group norm. }\end{array}$ & & & $\begin{array}{l}\text { Identify a member } \\
\text { of a different entity } \\
\text { by stating } \\
\text { characteristics that } \\
\text { are not common in } \\
\text { the group. }\end{array}$ \\
\hline 7 & 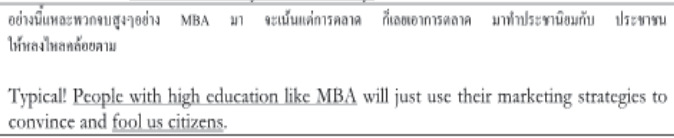 & & & & $\begin{array}{l}\text { Identify differences } \\
\text { of other group. }\end{array}$ \\
\hline 8 & 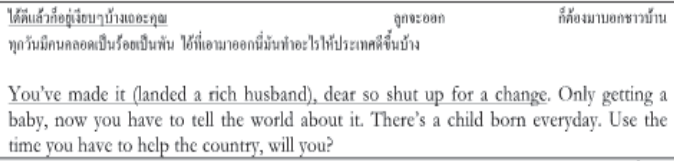 & $\begin{array}{l}\text { Judge based on } \\
\text { group norm. }\end{array}$ & & & \\
\hline \multirow[t]{2}{*}{9} & 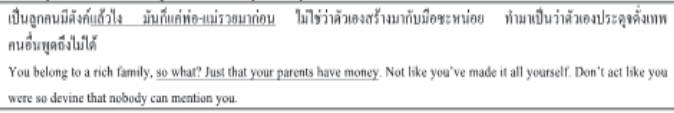 & & $\begin{array}{l}\text { Make the notion of } \\
\text { 'rich' insignificant. }\end{array}$ & & \\
\hline & Lower Class & & & & \\
\hline 10 & 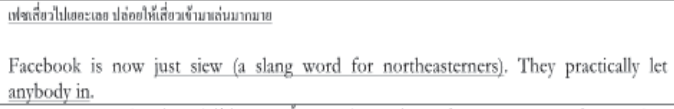 & & & & $\begin{array}{l}\text { Claim the domain as } \\
\text { their discourse } \\
\text { community. }\end{array}$ \\
\hline 11 & 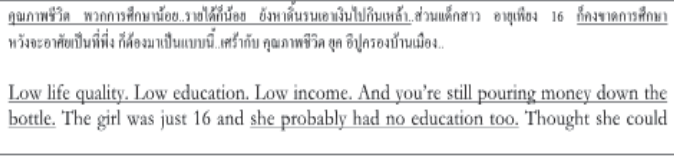 & $\begin{array}{l}\text { Based on the norm } \\
\text { that education is } \\
\text { ncecssary, evaluate } \\
\text { that people with } \\
\text { troubling lives lack } \\
\text { education as cause }\end{array}$ & & & \\
\hline
\end{tabular}




\begin{tabular}{|c|c|c|c|c|c|}
\hline & Comments & Shared culture & Solidarity/ & $\begin{array}{l}\text { Criticism/ } \\
\text { Conflict resolution }\end{array}$ & Group awareness \\
\hline & rely on him but ended up this way. So sad with this quality of life in the era of this PMI. & and effect. & & & \\
\hline 12 & 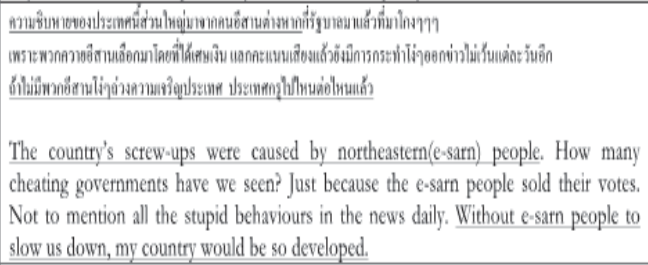 & & & $\begin{array}{l}\text { Assign } \\
\text { rcsponsibility to } \\
\text { another group. }\end{array}$ & $\begin{array}{l}\text { Identify a different } \\
\text { group based on } \\
\text { tegional } \\
\text { demographic. }\end{array}$ \\
\hline 13 & 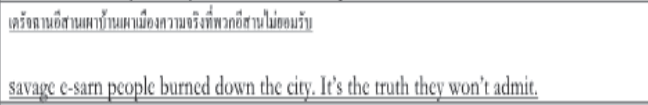 & $\begin{array}{l}\text { Indicate a statement } \\
\text { as a known fact by } \\
\text { all groups. }\end{array}$ & & & \\
\hline 14 & Remember! Prisons are for pariahs (low-class in Thai)! & & $\begin{array}{l}\text { State that the } \\
\text { addresses are prone } \\
\text { to commit crime } \\
\text { and are prone to } \\
\text { take the } \\
\text { consequence. }\end{array}$ & & \\
\hline 15 & 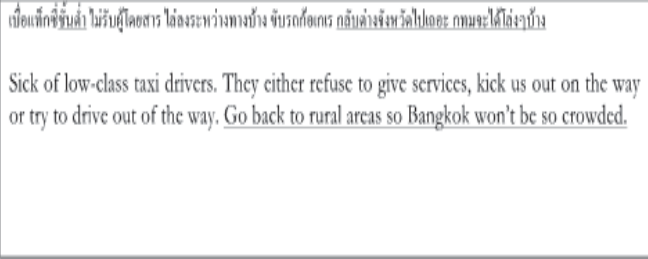 & & & & $\begin{array}{l}\text { Identify a } \\
\text { profession as lower } \\
\text { class. } \\
\text { State that the } \\
\text { addressec is not part } \\
\text { of the group, which } \\
\text { is represented by } \\
\text { Bangkok arca. }\end{array}$ \\
\hline
\end{tabular}

\section{Discussion}

To identify themselves, members of the group employ lexical items such as 'am', 'is', 'us' (postings 1, 2 \& 3) and referring to themselves explicitly collectively as 'middle class'. Group awareness is expressed through phrases such as 'like us' in postings $2 \& 4$. 'Like' is also used to set the awareness they have in several postings about other groups categorically.

At the discourse level, group solidarity is seen to be a very important strategy to display the sense of belonging in the discourse community of the middle class. The shared values and norms that the middle class employ are typically education, doing charity work, having high moral ethics, in postings $5,6 \& 7$, for example. Through the use of unspecific terms of address in posting 3 , the group assumes their sameness and groupism by categorically generalizing group status and membership.

The middle class express resentment of the disadvantageous conditions shared between them. Unfair taxation is used an obvious recurring theme in the discourse. At the same time, the middle class distinguish themselves from the other groups by stating norms and values upheld by the group and condemn behaviours that they claim are properties of the other groups that they do not endorse (postings 5, 6, 8 \& 11). These properties include pomposity and flamboyance of the upper class and liability of the lower class. Statements with items such as 'I don't care' and 'just' in postings 1 \& 9 , for example, are made to show their sense of indifference and hostility towards the upper class. Family ties are mentioned to make the notion of 'rich and famous' insignificant. The upper class's love of animals is counteracted by their disbelief in posting 5 .

Identification of the lower class was done through different strategies. First, it can be as explicit as naming another group 'pariah' in posting 14 or using a slang word that represents the origin of the northeastern part of Thailand in posting 13. In some comments, the identification of geographical background is together in the context as the identification of lower class. Second, the word of insult 'savage' (posting 13) is a clear example to show representation of the lower class. Third, in the discourse, the lower class are referred to in the discourse as the liability in the society (postings 11, 12 \& 15). Fourth, the strategy of territory marking is seen in several postings. The first one is the claim that Facebook did not use to be a domain for the lower class (posting 10). The second one is that the lower class are trouble and they belong to the prison (posting 14). The third one is to claim ownership of Bangkok as a place of middle class and they have the right to tell people from the northeast to go back to their place of origin (posting 15). In order to maintain good harmony within the 
group, a conflict is created towards the other classes, especially the lower class. The middle class assign the responsibility of the social problems to the lower class (posting 12) and that the society will be better off without the lower class (posting 15). Posting 13 is also an example of a statement that is made as a known fact shared by the middle class that the lower class were responsible for the unrest that happened in May 2010.

\section{Conclusion}

Class is the root of many problems in the Thai society. While the majority of people residing in Bangkok, the capital city, often view themselves as the major drive of the country, the reality is that it is the population under the poverty line that makes up the majority of the votes and controls the political conditions in general. Physical channels of discussion are scarce because Thai media are heavily controlled by the government. Online discussion is one way to voice their opinions when anonymity offers freedom of expression and makes possible dissenting debates.

Linguistic evidence from the study shows us that the middle class do seek harmony of other members of the same class and segregate themselves from other groups. The use of personal pronouns is clear evidence of the desire to establish the identity and relationships in the discourse community, similar to what is described in the study of van Compernolle, 2008). Language to show solidarity is used to mark the membership of the group.

The middle class view themselves as the victim in the society because they pay higher taxes and undergo hardships. They see the upper class as the group that are privileged and benefit from connections, education and wealth status. Although they may aspire for that position in the society, they derecognize it and deny any link to the upper class.

Shared valued and norms are used as the set rules to distinguish themselves against other groups. Judgments are based on their code of practice such as education, social manner and work and life ethics. Education is used as the benchmark to criticize the other groups. This is also seen as a way of constructing an identity for the audience to experience based on what they think the society desires.

This study shows that the discourse that displays social "inequality such as this is the structural result of historical process of social, political, cultural group dominance", (van Dijk, 1994, p. 23). It is useful for researchers in the field of sociolinguistics and applied linguistics, especially those with the focus on virtual identities and political online discourse. Individuals' language is a means of understanding what goes on in their society. Online community is like a playground. The discourse is like the social activities that the members are engaging in. While there is a large body of literature on the connections between language and identity, this study may be a fresh contribution to add on in investigation of lexical items and identity identification of human interaction within the concept of class in the society.

\section{References}

Buote, V., Wood, E. \& Pratt, M. (2009). Exploring similarities and differences between online and offline friendships: The role of attachment style. Computers in Human Behavior, 25(2), pp. 560-567.

Herring, S. C. (2004). Computer-mediated discourse analysis: An approach to researching online communities. In Sasha A. Barab, Rob Kling and James H. Gray(eds.) Designing for Virtual Communities in the Service of Learning. Cambridge, U.K. and New York: CUP. 338-376.

Hyland, K. (2011). The presentation of self in scholarly life: Identity and marginalization in academic homepages. English for Specific Purposes, 30(4), pp. 286-297

Koller, V. (2012). How to Analyse Collective Identity in Discourse - Textual and Contextual Parameters. Critical Approaches to Discourse Analysis across Disciplines, 5(2), pp. $19-38$.

Ravallion, M. (2010). The developing world's bulging (but vulnerable) middle class. World Development. 38(4), pp. $445-454$.

Scott, S. (2002) Linguistic feature variation within disagreements: An empirical investigation. Text 22(2) (2002), pp. 301-328.

Evers, Hans-Dieter. 1966. "The Formation of a Social Class Structure: Urbanization,

Bureaucratization and Social Mobility in Thailand." American Sociological Review, 31(4), 480-88.

Evers, Hans-Dieter. 1980. "Group Conflict and Class Formation in Southeast Asia." Pp.

247-61 in Sociology of Southeast Asia, edited by Hans-Dieter Evers. Kuala Lumpur: Oxford University Press.

Yus, F. (2001). Discourse and Identity. International Encyclopedia of the Social \& Behavioral Sciences. pp. 3728-3732.

Van Compernolle, R. (2008). Second-person pronoun use and address strategies in on-line personal ads from Quebec. Journal of Pragmatics, 40(12), pp. 2062-2076.

Van Dijk, T. (1994). Discourse and inequality. Lenguas Modernas, 2, pp. 19-37. 
